aims to assess which factors moderate the effect of youth unemployment on mental health measured in the midtwenties.

Methods We use data from Next Steps (formerly the Longitudinal Study of Young People in England) a cohort of secondary school children recruited at age 14 and followed up to age 25. We measure youth unemployment as six or more months worklessness between ages 18-20 (2008-2010), a period which includes the high youth unemployment rates which followed the global financial crisis. Our measure of mental health is the 12-Item General Health Questionnaire (GHQ) Likert score collected at age 25. We use multivariate OLS regression and add interaction terms to models to assess whether the association between youth worklessness and GHQ scores differs by: gender, locus of control (measured at age 15), parental socioeconomic class (age 14), and adolescent neighbourhood characteristics.

Results Our sample consists of 4,047 individuals, $14.4 \%$ of whom experienced six or more months worklessness between ages 18-20. Preliminary results show youth worklessness is associated with worse GHQ scores at age 25 (beta $=0.13,95 \%$ $\mathrm{CI}=0.043-0.218$ ), an association which is somewhat attenuated adjusting for GHQ scores at age 15 (beta $=0.08$, 95\% CI=0.006-0.168). Comparing across groups, a significant association is only found amongst males (beta $=0.18,95 \% \mathrm{CI}=0.056-$ 0.309 ) and individuals from low socioeconomic class backgrounds (beta $=0.13,95 \% \mathrm{CI}=0.043-0.218$ ). (Corresponding figures for females (beta $=0.017,95 \% \mathrm{CI}=-0.103-0.137$ ) and those from higher socioeconomic class backgrounds (beta $=0.012,95 \%$ $\mathrm{CI}=-0.098-0.122)$.) There is little evidence that locus of control moderates the association between youth worklessness and later mental health (F-test for difference in coefficients for above vs below median locus of control: $p=0.839$ ).

Conclusion These results suggest the scarring effects of youth unemployment may be confined to certain groups. Future research should examine why youth unemployment may signal future difficulties amongst some individuals and not others. Policymakers looking to improve the long-term outcomes of unemployed young people may consider focusing on particular groups.

\section{OP15 A LONGITUDINAL STUDY ON THE ASSOCIATION BETWEEN PERCEIVED NEIGHBOURHOOD CONDITIONS AND DEPRESSION IN 10,487 AGING EUROPEAN ADULTS: DO THE ASSOCIATIONS VARY BY EXPOSURE TO CHILDHOOD STRESSORS?}

${ }^{1} \mathrm{G}$ Baranyi ${ }^{*}$, ${ }^{2} \mathrm{~S}$ Sieber, ${ }^{1} \mathrm{~J}$ Pearce, ${ }^{2,3} \mathrm{~B}$ Cheval, ${ }^{1} \mathrm{C}$ Dibben, ${ }^{2,4} \mathrm{M}$ Kliegel, ${ }^{2,3} \mathrm{~S}$ Cullati. ${ }^{1} \mathrm{Centre}$ for Research on Environment, Society and Health, University of Edinburgh, Edinburgh, UK; ${ }^{2}$ Swiss NCCR 'LIVES - Overcoming Vulnerability: Life Course Perspectives', University of Geneva, Geneva, Switzerland; ' ${ }^{3}$ Department of General Internal Medicine, University of Geneva, Geneva, Switzerland; ${ }^{4}$ Center for the Interdisciplinary Study of Gerontology and Vulnerability, University of Geneva, Geneva, Switzerland

\subsection{6/jech-2019-SSMabstracts. 15}

Background Emerging literature emphasises the association between neighbourhood conditions and late life depression. Childhood experiences, crucial for life course development of mental health, may modify how neighbourhood affects subsequent depression. This study assessed the longitudinal associations between perceived neighbourhood and depression among older adults, and tested whether these associations varied by exposure to different childhood stressors.
Methods Data were drawn from the cross-national SHARE Survey, a 10-year probability sampled cohort study, representative for European adults aged 50 and over. Non-institutionalised respondents were included, if they provided answers on neighbourhood and depression at baseline (waves 1 or 2), participated in the life history assessment (wave 3), and had at least one assessment of depression during the follow-up (waves 4-6). Neighbourhood was assessed with four binary questions, capturing the subjective perception of access to services (public transportation, neighbourhood amenities) and neighbourhood nuisance (crime, air pollution and environmental problems) in the area surrounding the place of residence. Childhood stressors, defined as socioeconomic conditions, adverse experiences and health problems, were derived from retrospectively collected questions. Depression was measured with the EURO-D scale; the cut-off score of $\geq 4$ indicated clinically significant levels of depressive symptoms. Multilevel logistic regression estimated the risk of depression. We conducted sensitivity analyses by using continuous EURO-D scores in multilevel linear regression and adjusting final models for urban-rural difference. All models were conducted in R Studio.

Results The final sample comprised 10,487 participants with 18,899 observations during follow-up, living in 13 European countries. After controlling for sociodemographic and health covariates, as well as baseline depression, access to services were negatively $(\mathrm{OR}=0.81,95 \%$ CI $0.71-0.93)$ and neighbourhood nuisance positively $(\mathrm{OR}=1.29$, 95\% CI 1.12-1.47) associated with depression during follow-up. We found interactions between neighbourhood and childhood socioeconomic conditions, but not with adverse experiences and health problems. While older adults who grew up in better childhood socioeconomic conditions benefited more from living in a residential area with good access to services, they were at higher risk of developing depression when residing in areas with more neighbourhood nuisances.

Conclusion Older adults' mental health can benefit from better access to services, while neighbourhood nuisance increase the risk of depression. Importantly, socioeconomic circumstances in early life may influence vulnerability to neighbourhood effects. Limitations, concerning self-reported measures and retrospectively collected childhood indicators warrant for cautious interpretations. Future research on neighbourhood effects should prioritise the implementation of the life course approach, while policy should consider neighbourhood as a public health opportunity supporting healthy ageing.

\section{Cardiovascular Disease}

\section{OP16 ASSOCIATIONS OF CHOLESTEROL TARGETS AND MORTALITY WITH STATIN ADHERENCE IN NHS GREATER GLASGOW \& CLYDE'S POST MYOCARDIAL INFARCTION POPULATION}

${ }^{1} \mathrm{R}$ Brown*, ${ }^{2} \mathrm{~S}$ Wild, ${ }^{3} \mathrm{~J}$ Lewsey, ${ }^{1} \mathrm{P}$ Welsh, ${ }^{1} \mathrm{~J}$ Logue. ${ }^{1}$ Institute of Cardiovascular and Medical Science, University of Glasgow, Glasgow, UK; ${ }^{2}$ Usher Institute of Population Health Sciences and Informatics, University of Edinburgh, Edinburgh, UK; ${ }^{3}$ Institute of Health and Wellbeing, University of Glasgow, Glasgow, UK

\subsection{6/jech-2019-SSMabstracts. 16}

Background Under SIGN cardiovascular disease guidelines (2007, 2017), patients $>40$ years in Scotland are classified as being at high or low risk of a CVD event in the next ten 